\title{
The impact of proposed regulatory changes and rescheduling on low-dose codeine purchasing in Canada: a time-series analysis
}

\author{
Charlotte G. Boone PharmD, Tony Antoniou PhD, David N. Juurlink MD PhD, \\ Teagan Rolf von den Baumen BSc PharmD, Sophie A. Kitchen MSc, Georgia C. Richards BSc, \\ Mina Tadrous PharmD PhD, Tara Gomes PhD
}

Abstract

Background: Low-dose codeine products can be purchased without a prescription in most of Canada. We explored trends in the purchasing of these products across the Canadian provinces from 2014 to 2019, evaluating the impact of Health Canada's 2016 announcement of a proposed regulatory change and the 2017 opening of a 60-day public comment period, as well as the impact of Manitoba's 2016 policy change requiring a prescription for the purchase of all codeine products in that province.

Methods: We evaluated population-adjusted monthly purchasing of codeine products from January 2014 to October 2019 using the IQVIA Canadian Drug Store and Hospital Purchases Audit database, stratified by province and over-the-counter (OTC) status. The primary outcomes were change in the monthly volume of low-dose codeine purchased after the 2016 federal regulatory proposal and the 2017 period of public comment across the provinces. Our secondary analysis was the impact of Manitoba's policy change in February 2016 requiring a prescription for low-dose codeine. We conducted a time-series analysis using interventional autoregressive integrated moving average models.

Results: Over the study period, $24120 \mathrm{~kg}$ of codeine (3.025 billion units) and $937867 \mathrm{~kg}$ of acetaminophen were sold as OTC, lowdose codeine products across the Canadian provinces. Health Canada's 2016 announcement did not significantly affect OTC codeine purchasing $(p=0.57)$. The initiation of a 60 -day public comment period was associated with a roughly $44 \%$ decrease in OTC codeine purchasing $(p=0.03)$. In Manitoba, purchasing of the same codeine formulations decreased after rescheduling in February $2016(p<0.001)$. We observed no significant change in the rate of purchasing of higher dose codeine formulations in response to scheduling changes in Manitoba $(p=0.22)$.

Interpretation: Although Health Canada's 2016 announcement of a proposed regulatory change did not appear to have an effect on OTC codeine purchasing nationally, the 60-day comment period was associated with a decrease in purchasing. Further, Manitoba's 2016 policy change was associated with a significant and sustained decrease in the overall volume of codeine purchased. Given the potential risks of codeine dependence and acetaminophen toxicity with these products, a national rescheduling strategy should be considered.

\begin{abstract}
T n Canada, the opioid crisis has affected every region of the country. ${ }^{1}$ Recently, all provinces (excluding Quebec) have made efforts to monitor opioid prescribing through implementation of prescription monitoring programs. $^{2-4}$ However, purchases of over-the-counter (OTC), low-dose codeine products are not accounted for in these systems. Although codeine is available only by prescription in many countries, low-strength products are available OTC in the United Kingdom, Canada and Ireland, among others. ${ }^{5}$ The accessibility of OTC codeine formulations reinforces the perception of safety that can contribute to hazardous use, ${ }^{6}$ dependence ${ }^{5,7}$ and other harms, including from the acetylsalicylic acid or acetaminophen with which the codeine is combined. ${ }^{7,8}$

In Canada, The Controlled Drugs and Substances Act defines OTC (Schedule II) codeine preparations as those containing
\end{abstract}

no more than $8 \mathrm{mg}$ or its equivalent of codeine phosphate per unit of solid form, or no more than $20 \mathrm{mg}$ codeine phosphate per $30 \mathrm{~mL}$ of liquid preparation. ${ }^{9}$ Additionally, these products must contain 2 or more additional medicinal ingredients of specified quantities. ${ }^{9}$ The most commonly sold OTC codeine

Competing interests: Georgia Richards reports support from the National Institute for Health Research School for Primary Care Research, the Naji Foundation and the Rotary Foundation during the conduct of the study, outside the submitted work. No other competing interests were declared.

This article has been peer reviewed.

Correspondence to: Tara Gomes, tara.gomes@unityhealth.to

CMAJ Open 2021 December 14. DOI:10.9778/cmajo.20210173 
preparations in Canada contain codeine, acetaminophen and caffeine. Although intended to prevent inappropriate use, the requirement for OTC codeine products to be combined with other medicinal ingredients places consumers at risk of toxicity from these drugs, in addition to opioid-related harm, ${ }^{8,10}$ particularly hepatotoxicity caused by acetaminophen. ${ }^{11,12}$

In Canada, the federal government is responsible for determining the conditions of sale of drug products, such as the requirement for a prescription. Provincial and territorial governments can specify additional conditions of sale, but those conditions must be more restrictive than federal legislation. ${ }^{13}$ On Feb. 1, 2016, the College of Pharmacists of Manitoba mandated that all low-dose codeine preparations previously considered OTC would require a prescription by a pharmacist or other prescriber. ${ }^{14}$ Similar regulations have been proposed on a provincial ${ }^{15}$ and national ${ }^{16}$ level, and are supported by professional pharmacy and medical associations. ${ }^{17,18}$

In July 2016, Canada's minister of health proposed regulatory changes that would require a prescription for low-dose codeine products, and in September 2017, Health Canada opened a 60-day comment period for the proposed regulatory change. ${ }^{16}$ Changes to the scheduling of OTC codeine products are still being proposed, with ongoing consultations with stakeholders. ${ }^{19}$

To limit the risk of harm from these products, it is important to understand the volume of products being sold across the country and the impacts, if any, of restrictions or proposed rescheduling on their sale. We explored trends in the purchasing of low-dose codeine products across the Canadian provinces from 2014 to 2019, evaluating the impact of federal regulatory proposals on patterns of use, as well as the impact of Manitoba's 2016 policy change requiring a prescription for the purchase of codeine products in that province.

\section{Methods}

\section{Study design and setting}

We conducted a population-based, time-series analysis of low-dose codeine purchasing by pharmacies and hospitals across the Canadian provinces from Jan. 1, 2014, to Oct. 31, 2019. Data regarding codeine consumption in the Canadian territories were not available for this analysis.

\section{Data sources}

We used the IQVIA Canadian Drug Store and Hospital Purchases Audit $(\mathrm{CDH})$ database during the study period. IQVIA's CDH is a projected audit. Sampling covers over one-third of all retail pharmacies (about 3000 pharmacies) and $88 \%$ of hospitals (about 800 hospital sector outlets) in Canada. Data are subsequently stratified by size, region and outlet type, and total market volume is then projected for each product by region. Within the drug store and retail sector, projections for $98 \%$ of products fall within $12.5 \%$ of their true activity at the national level. Based on the previous 72 months (ending April 2021), 99\% of all codeine-related purchases (including OTC products) came from retail pharmacies (J. Gaudet, IQVIA, Kirkland, Que.: personal communication, 2021). We used annual population estimates from Statistics Canada for 2014 to 2019 to adjust consumption rates in each province to its population. ${ }^{20}$

\section{Outcomes}

Our primary outcomes were the change in monthly volume of low-dose codeine purchased after the federal regulatory proposal regarding a change to prescription-only status and the subsequent 60-day period of public comment across the Canadian provinces. For this analysis, we excluded data from Manitoba because low-dose codeine products were rescheduled as prescription-only during the study period. The volume of dispensed low-dose codeine "units" allowed for standardization between liquid and solid dosage forms. We defined 1 unit as $8 \mathrm{mg}$ of codeine, the standard dose in 1 OTC tablet.

In a secondary analysis, we investigated the impact of Manitoba's policy change in February 2016, requiring a prescription for low-dose codeine. We evaluated several measures, including the monthly purchasing volume of low-dose codeine products, higher-dose codeine products (which have always required a prescription) and all codeine products combined. We sought to determine whether restrictions on the sale of OTC codeine products were associated with a compensatory increase in the use of higher-dose codeine products.

\section{Statistical analysis}

We used interventional autoregressive integrated moving average (ARIMA) models to evaluate the impact of regulatory proposals and policy changes on monthly purchasing of codeine at a population-adjusted rate in Canadian provinces. We differenced the time series and used the augmented Dickey-Fuller test to confirm stationarity. We selected model parameters using the residual autocorrelation function (ACF), partial ACF, and inverse ACF correlograms. We chose the final model using the autocorrelation plots, the Ljung-Box $\chi^{2}$ test for white noise and the $R^{2}$ estimate of fit. In the primary analysis, we modelled Health Canada's proposed regulatory changes (July 2016) and the opening of the 60-day public comment period on these regulatory changes (September 2017) as ramp functions to test for gradual changes in trends.

In our secondary analysis of codeine purchasing in Manitoba, we analyzed the impact of the February 2016 scheduling change on monthly sales of codeine-containing products. In separate models, we used a step intervention function to test for an immediate change in total codeine purchasing and in low-dose codeine purchasing, and a ramp intervention function to test for a gradual slope change in purchasing of higher-dose codeine products. We completed all analyses using SAS Enterprise Guide version 9.4 and the SAS/ETS Time Series Forecasting System.

\section{Ethics approval}

Given the aggregate nature of the source data, research ethics approval was not required. 


\section{Resulits}

From January 2014 to October 2019, $24120 \mathrm{~kg}$ of codeine (3.025 billion units), together with $937867 \mathrm{~kg}$ of acetaminophen, were sold as OTC, low-dose codeine products across the Canadian provinces. After population adjustment, this amounts to about 88 codeine tablets dispensed OTC for every resident of the Canadian provinces over a period of about 5 years, or roughly 18 tablets per resident per year.

\section{Impact of selected opioid policies and interventions}

In our primary analysis of low-dose codeine purchasing across the Canadian provinces, we found that the proposed regulatory change announced in 2016 was not significantly associated with low-dose codeine purchasing (ramp function $p=0.574$ ). In contrast, the subsequent announcement of a 60-day comment period in September 2017 was associated with a $43.5 \%$ decrease in low-dose codeine purchasing, from 1.38 units per resident in August 2017 to 0.78 units in October 2019 (ramp function $p=0.03$ ) (Figure 1; Appendix 1, available at www. cmajopen.ca/content/9/4/E1181/suppl/DC1).

In the secondary analysis of Manitoba trends, the February 2016 policy change was associated with an immediate $92.3 \%$ reduction in purchasing of low-dose codeine products by step function, from 3.50 units per resident in January 2016 to
0.27 units in February 2016 (step function $p<0.001$ ) (Figure 2, Appendix 1). The scheduling change was not associated with compensatory changes in purchasing of higher-dose prescription codeine formulations (ramp function $p=0.22$; Figure 2, Appendix 1) and was associated with a significant decrease in overall codeine purchasing (step function $p<0.001$; Figure 2, Appendix 1).

\section{Cross-provincial comparison of low-dose codeine purchasing}

In the final year of our study period (Nov. 1, 2018, to Oct. 31, 2019), 375847016 units of low-dose codeine preparations were sold across the provinces, including Manitoba, representing $3007 \mathrm{~kg}$ of codeine and $114703 \mathrm{~kg}$ of acetaminophen. In Manitoba, where codeine products were available only with a prescription for this period, low-dose products accounted for $3.3 \%$ of all codeine sold by weight, compared with $21.7 \%$ overall in all Canadian provinces, whereby all other provinces have lowdose codeine products available for OTC sale (Table 1). We identified considerable interprovincial variability in the rate of OTC codeine purchasing, from 1.6 units per person in Quebec to 17.3 units per person in British Columbia. The percentage of codeine attributable to low-dose preparations also varied by province, from $6.9 \%$ of all codeine purchased in Alberta to $44.6 \%$ of all codeine purchased in Ontario.

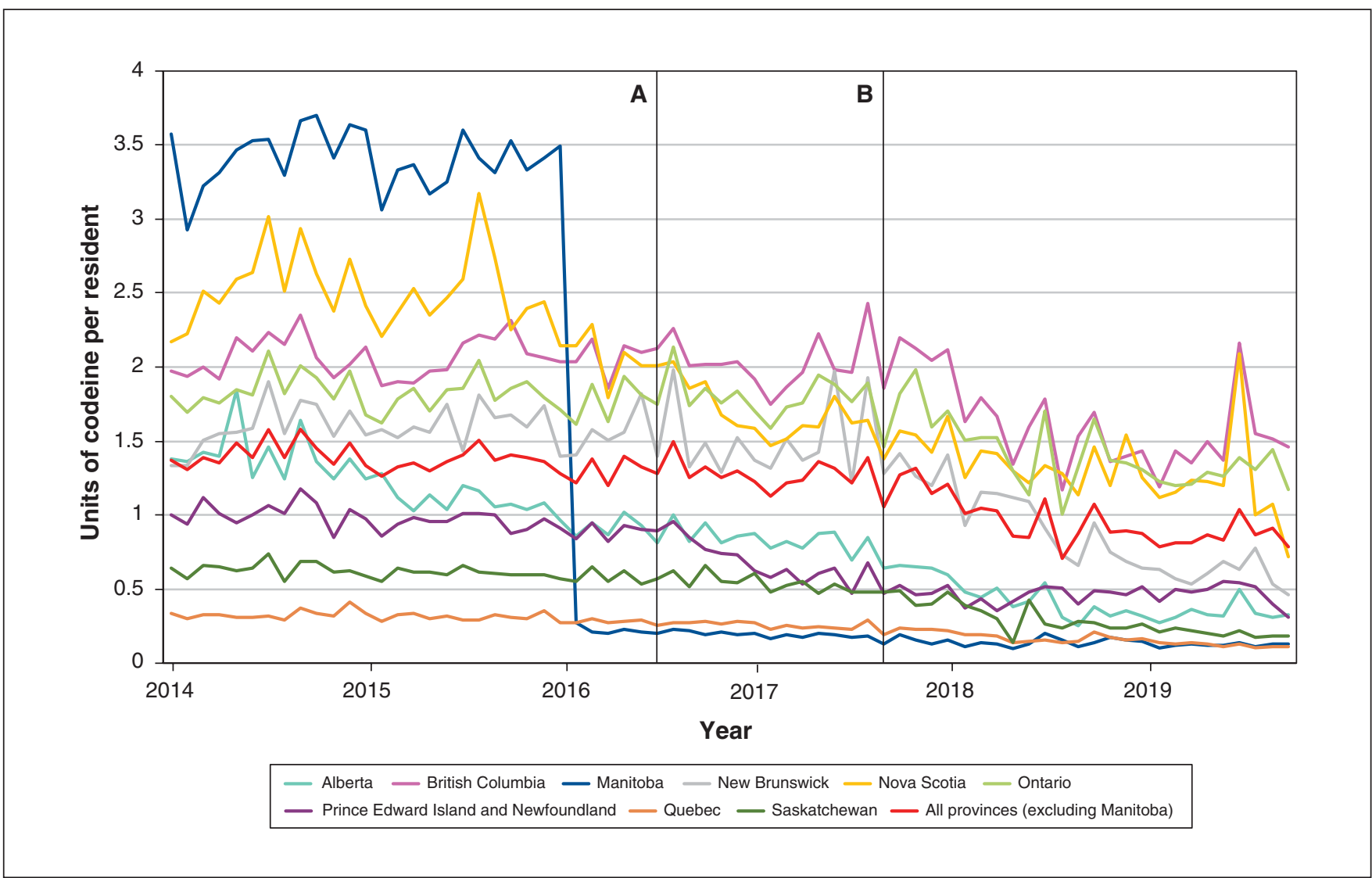

Figure 1: Low-dose codeine purchasing, in units per resident per month (1 unit = $8 \mathrm{mg}$ ), among the Canadian provinces from January 2014 to October 2019. Vertical bars indicate policy changes. Note: A = Health Canada's proposal of regulatory changes on July 17,$2016 ; \mathrm{B}=\mathrm{Health}$ Canada's 60-day public commenting period opened on Sept. 9, 2017. 


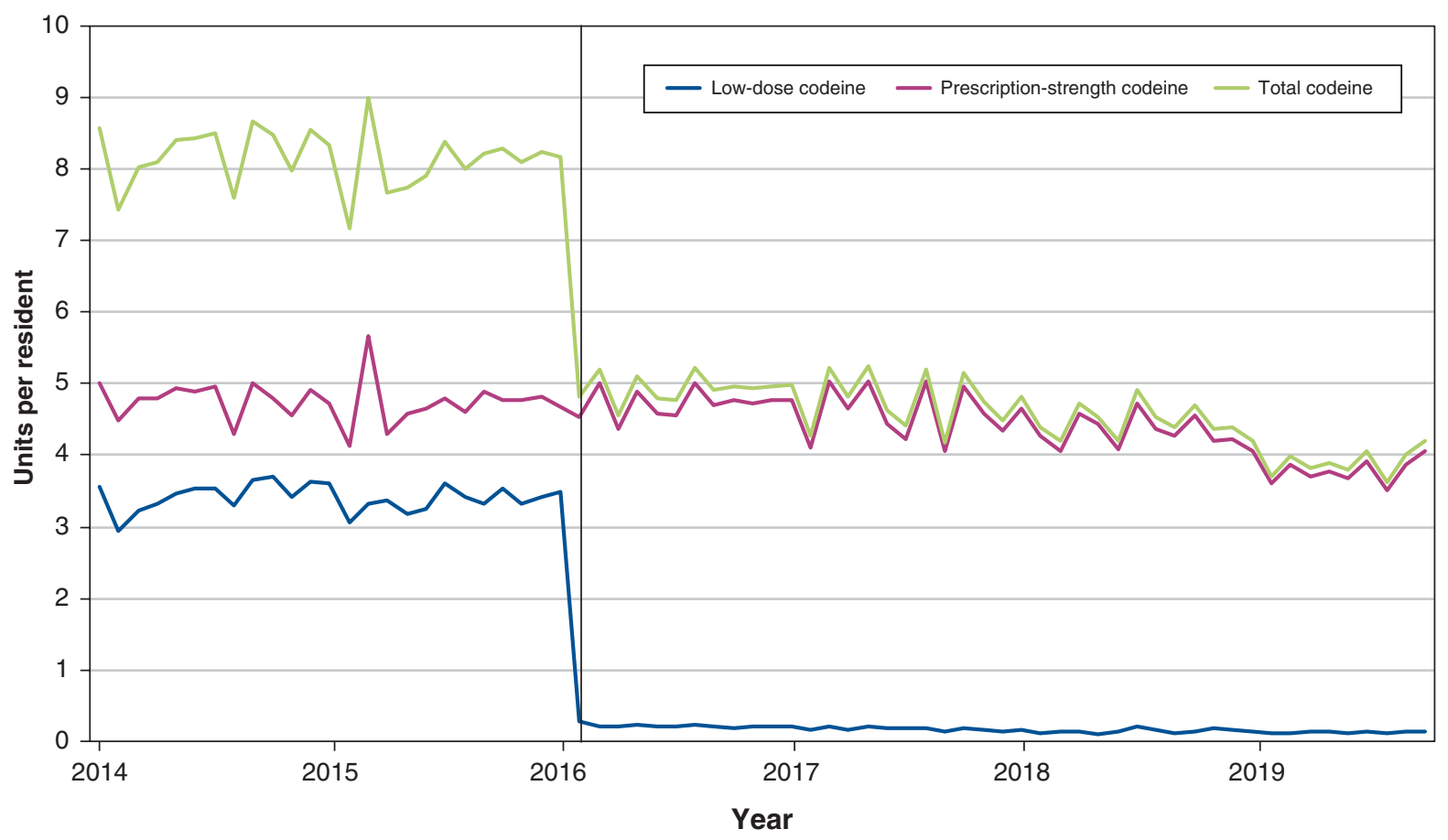

Figure 2: Purchasing of over-the-counter (low-dose), prescription-strength codeine products, and total codeine purchased, in units per resident per month (1 unit $=8 \mathrm{mg}$ ) in Manitoba from January 2014 to October 2019. Vertical bar indicates policy change on Feb. 1, 2016, which required a prescription for all codeine products, regardless of strength.

\section{Interpretation}

In this population-based time-series analysis, we found that more than 375 million low-dose codeine tablets were dispensed without a prescription in Canada in the most recent 1-year period of the study, from Nov. 1, 2018, to Oct. 31, 2019. This represents about 10 tablets sold for every resident within Canada's provinces; over one-fifth of all codeine dispensed (by weight) in the Canadian provinces was sold without a prescription. Although we observed interprovincial variation in OTC codeine dispensing across Canada, these trends were consistent with patterns of prescription opioid dispensing that have been reported previously, which suggests relatively strong alignment between regional patterns of OTC and prescription opioid use across the country. ${ }^{20,21}$ Interestingly, although the announcement of proposed national regulatory changes to OTC codeine products had no impact on OTC codeine accessibility, the initiation of a public commenting period was associated with reduced purchasing. In addition, rescheduling of low-dose codeine products in Manitoba was associated with an immediate and striking decrease in the total volume of these products sold, with no compensatory increase in higher-dose prescription codeine purchasing, and a significant decrease in the overall volume of codeine purchased. This shows the potential impact of rescheduling in Canada, if applied nationally.
The decrease in codeine purchasing observed after the opening of a comment period suggests that the engagement of stakeholders in regulatory discussion influenced consumption trends. This may indicate that media coverage ${ }^{22}$ and communication to clinicians regarding the potential regulatory changes from their college ${ }^{23}$ increased public awareness of the potential risks of codeine, and may have influenced consumption trends and pharmacist counselling. The observed reduction in sales of low-dose codeine products is suggestive of a therapeutic area in which consumers and health care providers are willing to consider alternative therapies. Ongoing policy discussions should consider this as an indication of the ability for pharmacists and patients to adapt to changing regulation around these products, if introduced nationally.

This is further reinforced by our findings in Manitoba, which are consistent with a study that evaluated the 2018 rescheduling of low-dose codeine in Australia. ${ }^{24}$ In both of these studies, purchasing of low-dose codeine preparations declined immediately after the policy change, with no compensatory change in purchasing of high-dose formulations. The consistency of these findings suggests that rescheduling low-dose codeine preparations may reduce potentially unsafe use of these products without shifts in treatment toward higher-strength alternatives.

It is also important to consider how changes in analgesic availability, in the absence of improved access to other pain 


\begin{tabular}{|c|c|c|c|c|c|c|c|}
\hline \multirow[b]{2}{*}{ Province } & \multicolumn{3}{|c|}{ Units of codeine* } & \multicolumn{2}{|c|}{ Codeine sales } & \multicolumn{2}{|c|}{ Acetaminophen sales } \\
\hline & $\begin{array}{l}\text { No. } \\
\text { of units }\end{array}$ & $\begin{array}{l}\text { Rate, } \\
\text { units per } \\
\text { resident }\end{array}$ & $\begin{array}{l}\% \text { of total } \\
\text { codeine } \\
\text { sold as } \\
\text { OTC† }\end{array}$ & $\begin{array}{l}\text { Codeine, } \\
\text { kg }\end{array}$ & $\begin{array}{l}\text { Rate, mg } \\
\text { per } \\
\text { resident }\end{array}$ & $\begin{array}{l}\text { Acetaminophen, } \\
\mathrm{kg}\end{array}$ & $\begin{array}{l}\text { Rate, mg } \\
\text { per } \\
\text { resident }\end{array}$ \\
\hline Alberta & 17688955 & 4.0 & 6.9 & 142 & 32.4 & 5375 & 1229.6 \\
\hline British Columbia & 89681975 & 17.7 & 38.0 & 718 & 141.5 & 26500 & 5225.3 \\
\hline Manitoba & 2175128 & 11.6 & 3.3 & 17 & 12.7 & 753 & 549.7 \\
\hline New Brunswick & 5836590 & 7.5 & 21.5 & 47 & 60.1 & 1788 & 2301.4 \\
\hline Nova Scotia & 14369659 & 14.8 & 40.5 & 115 & 118.3 & 4462 & 4593.8 \\
\hline Ontario & 225685892 & 15.5 & 44.6 & 1806 & 123.9 & 69698 & 4784.8 \\
\hline $\begin{array}{l}\text { Prince Edward Island, } \\
\text { Newfoundland and } \\
\text { Labrador }\end{array}$ & 3853873 & 5.7 & 11.9 & 31 & 45.4 & 1443 & 2127.0 \\
\hline Quebec & 13570422 & 1.6 & 19.3 & 109 & 12.8 & 3730 & 439.6 \\
\hline Saskatchewan & 2984521 & 2.5 & 9.3 & 24 & 20.3 & 954 & 812.6 \\
\hline All provinces & $375847016 \ddagger$ & 10.0 & 21.7 & $3007 \S$ & 80.3 & 114703 & 2451.5 \\
\hline \multicolumn{8}{|c|}{$\begin{array}{l}\text { Note: OTC = over-the-counter. } \\
\text { * } 1 \text { unit }=8 \mathrm{mg} \text {. } \\
\text { tReported as a percent of total mass of codeine sold. } \\
\text { flf the dosage form was not sold in } 8 \mathrm{mg} \text { units, we converted the volume to these standard units. Therefore, the provincial total does not equal the sum of } \\
\text { provinces because of rounding error. } \\
\text { §Weights have been rounded to the nearest kilogram. }\end{array}$} \\
\hline
\end{tabular}

management modalities, can lead to unintended consequences, such as a corresponding shift to other, potentially less safe alternatives, both prescribed and nonprescribed. In Australia, the rescheduling of codeine products led to significant increases in nonopioid OTC analgesic use, ${ }^{25}$ suggesting that, in some patients, safer approaches were used to manage pain. However, more data are needed to determine the degree to which patients who were previously accessing OTC codeine were able to successfully manage their pain with nonopioid analgesics, or whether they transitioned to more potent opioids. Although it is reassuring that the 2018 rescheduling in Australia resulted in an abrupt decrease in monthly codeine-related poisonings (as captured by calls to the New South Wales Poisons Information Centre $)^{25}$, future work should explore whether Manitoba's regulatory change led to any patient harm, including potential switches from prescription codeine to the unregulated opioid supply. This work could identify important opportunities for clinicians and policy-makers to support patients who are currently accessing OTC codeine through a transition in therapy if regulatory changes are expanded further across Canada.

\section{Limitations}

The data used in our study represent codeine purchasing by pharmacies, and may not be reflective of consumption patterns, as products may expire and be discarded, or be purchased by an individual and not completely consumed. However, pharmaceutical purchasing analysis methods are often used in antimicrobial stewardship analyses, as they strongly correlate with consumption patterns, ${ }^{26}$ and such data are likely to provide an estimate of community consumption. Although these data represent purchasing by both hospitals and retail pharmacies, $99 \%$ of the codeine-related product purchases (including OTC products) captured in this data set were made by retail pharmacies (J. Gaudet, IQVIA, Kirkland, Que.: personal communication, 2021), which suggests that our findings are largely representative of community-based trends. It is possible that the observed declines in OTC codeine were influenced by other factors beyond the federal regulatory proposals, including increased public awareness of opioid-related harm and alternative pain control suggestions by health care professionals. However, despite changes in public awareness of opioid-related harm and opioid-related policies over time, no specific policy changes or clinical practice guideline changes were implemented in September 2017 that would explain the accelerated decline in OTC sales occurring at this time. Therefore, it is possible that the findings observed are related to Health Canada's commenting period rather than other external factors. Data on purchasing of nonopioid, OTC analgesic products and data from the territories were not available; thus, we could not evaluate trends in alternative pain management approaches or trends in OTC codeine sales in the territories. Finally, we could not determine whether the rescheduling of low-dose codeine in Manitoba led to adverse patient outcomes, including opioid withdrawal, use of unregulated opioids or adverse outcomes from increased use of alternative analgesics. 


\section{Conclusion}

Despite a trend toward lower use over time, the overall volume of low-dose codeine purchasing by pharmacies remains high, with an annual rate of 10 tablets purchased by pharmacies for every resident of the Canadian provinces in 2019. Manitoba's rescheduling of these products in 2016 shows the potential for rapid, large decreases in low-dose codeine purchasing across Canada if such a change were implemented nationally. Given the risks of medication-related harm and dependence associated with low-dose codeine products, there is an opportunity for federal regulatory changes to improve medication safety across Canada.

\section{References}

1. Belzak L, Halverson J. The opioid crisis in Canada: a national perspective. Health Promot Chronic Dis Prev Can 2018;38:224-33.

2. Gomes T, Juurlink D, Yao Z, et al. Impact of legislation and a prescription monitoring program on the prevalence of potentially inappropriate prescriptions for monitored drugs in Ontario: a time series analysis. CMAZ Open 2014;2:E256-61.

3. Position statement: sale of exempted codeine preparations. Halifax: Nova Scotia College of Pharmacists; 2015.

4. Sproule B. Prescription monitoring programs in Canada: best practice and program review. Ottawa: Canadian Centre on Substance Abuse; 2015.

5. Nielsen S, Van Hout MC. Over-the-counter codeine-from therapeutic use to dependence, and the grey areas in between. Curr Top Behav Neurosci 2017; 34:59-75.

6. Wells JS, Bergin M, Van Hout M-C, et al. Purchasing over the counter (OTC) medicinal products containing codeine: easy access, advertising, misuse and perceptions of medicinal risk. 7 Pharm Pharm Sci 2018;21:30049.

7. McAvoy BR, Dobbin MDH, Tobin CL. Over-the-counter codeine analgesic misuse and harm: characteristics of cases in Australia and New Zealand. NZ Med 7 2011;124:29-33.

8. Nielsen S, Murnion B, Dunlop A, et al. Comparing treatment-seeking codeine users and strong opioid users: findings from a novel case series. Drug Alcohol Rev 2015;34:304-11.

9. Narcotic Control Regulations (C.R.C., c. 1041). Ottawa: Government of Canada; 2020 Jan. 16, amended 2019 Dec. 9. Available: https://laws-lois.justice.gc.ca/ eng/Regulations/C.R.C.,_c._1041/index.html (accessed 2020 May 20).

10. Arora S, Roxburgh A, Bruno R, et al. A cross-sectional analysis of over-thecounter codeine use among an Australian sample of people who regularly inject drugs. Drug Alcobol Rev 2013;32:574-81.

11. Blieden M, Paramore LC, Shah D, et al. A perspective on the epidemiology of acetaminophen exposure and toxicity in the United States. Expert Rev Clin Pharmacol 2014;7:341-8.

12. Ghanem CI, Perez MJ, Manautou JE, et al. Acetaminophen from liver to brain: new insights into drug pharmacological action and toxicity. Pharmacol Res 2016;109:119-31.

13. Drug scheduling in Canada: general overview. Ottawa: National Association of Pharmacy Regulatory Authorities (NAPRA). Available: https://napra.ca/drug -scheduling-canada-general-overview (accessed 2020 July 14).

14. Zlomislic D, Yang J. Manitoba sets new rule banning non-prescription codeine. Toronto Star 2016 Jan. 13, updated 2016 Feb. 1. Available: https:// www.thestar.com/life/health_wellness/2016/01/13/manitoba-sets-new-rule -limiting-codeine.html (accessed 2020 Aug. 23).

15. Samoila K. Exempted codeine products (ECPs): proposed regulatory bylaw amendments: stakeholder consultation [memorandum]. Regina (SK): Saskatchewan College of Pharmacy Professionals (SCPP); 2018.

16. Controlled Drug and Substances Act: notice to interested parties - Non-prescription availability of low-dose codeine products. In: Canada Gazette, Part I, Vol. 151, No. 136: Government Notices. Ottawa: Government of Canada; 2017. Available: https://gazette.gc.ca/rp-pr/p1/2017/2017-09-09/html/notice-avis -eng.html (accessed 2020 Aug. 23)

17. CMA submission on non-prescription availability of low-dose codeine products. Ottawa: Canadian Medical Association (CMA). Available: https://policybase. cma.ca/documents/BriefPDF/BR2018-04.pdf (accessed 2020 Sept. 10).

18. Krawchenko I. Canadian Pharmacists Association submission re: non-prescription availability of low-dose codeine products. Ottawa: Canadian Pharmacists Association; 2017. Available: https://www.pharmacists.ca/cpha-ca/assets/File/ cpha-on-the-issues/CPhA\%20Submission\%20to\%20HC_Codeine\%2011_08_ 17.pdf (accessed 2020 Sept. 10).

19. Forward Regulatory Plan 2021-2023: proposed regulations amending the narcotic control regulations under the Controlled Drugs and Substances Act to make all products containing codeine available by prescription only while ensuring access to these medications. Ottawa: Government of Canada; modified 2021
Apr. 1. Available: https://www.canada.ca/en/health-canada/corporate/about -health-canada/legislation-guidelines/acts-regulations/forward-regulatory-plan/ plan/codeine-prescription.html (accessed 2021 Sept. 2).

20. Annual demographic estimates: Canada, provinces and territories. Ottawa: Statistics Canada. Cat. no. 91-215-X. Available: https://www150.statcan.gc.ca/n1/en/ catalogue/91-215-X (accessed 2020 Mar. 7).

21. Gomes T, Mastorakos A, Paterson JM, et al.; Canadian Network for Observational Drug Effect Studies Investigators. Changes in the dispensing of opioid medications in Canada following the introduction of a tamper-deterrent formulation of long-acting oxycodone: a time series analysis. CMAF Open 2017;5:E800-7.

22. Blackwell T. Ottawa proposes making OTC codeine pills prescription-only after years of pressure. National Post [Toronto] 2017 Sept. 11. Available: https:// nationalpost.com/health/ottawa-proposes-making-otc-codeine-pills-prescription -only-after-years-of-pressure\#: :text=the\%20industrialized\%20world.-,Ottawa $\% 20$ proposes $\% 20$ making $\% 20$ OTC\%20codeine \% 20pills\%20prescription \%2Donly\%20after\%20years, with\%20acetaminophen \%20or\%20other\%20 painkillers (accessed 2021 Apr. 28).

23. Health Canada consultation: OTC codeine products. The Island Capsule. Charlottetown: Prince Edward Island College of Pharmacy; 2017. Available: https://pepharmacists.ca/wp-content/uploads/2020/09/Island-Capsule-Edition -3-Volume-30.pdf (accessed 2021 Mar. 22).

24. Cairns R, Schaffer AL, Brown JA, et al. Codeine use and harms in Australia: evaluating the effects of re-scheduling. Addiction 2020;115:451-9.

25. Schaffer AL, Cairns R, Brown JA, et al. Changes in sales of analgesics to pharmacies after codeine was rescheduled as a prescription only medicine. Med 7 Aust 2020;212:321-7.

26. Tan C, Ritchie M, Alldred J, et al. Validating hospital antibiotic purchasing data as a metric of inpatient antibiotic use. 7 Antimicrob Chemother 2016;71:547-53.

Affiliations: Centre for Addiction and Mental Health (Boone); Li Ka Shing Knowledge Institute (Antoniou, Kitchen, Gomes), St. Michael's Hospital; ICES Central (Antoniou, Juurlink, Tadrous, Gomes); Department of Family and Community Medicine (Antoniou), University of Toronto, Toronto, Ont.; London Health Sciences Centre (Rolf von den Baumen), London, Ont.; Nuffield Department of Primary Care Health Sciences (Richards), University of Oxford, Oxford, UK; Women's College Hospital (Tadrous); Institute for Health Policy, Management, and Evaluation (Gomes), University of Toronto, Toronto, Ont.

Contributors: All authors made substantial contributions to the conception and design of the work. Charlotte Boone and Tara Gomes were responsible for data analysis. All authors contributed to data interpretation. Charlotte Boone and Tara Gomes drafted the work, and all other authors revised it critically for important intellectual content. All authors provided final approval of the version to be published and agree to be accountable for all aspects of the work in ensuring that questions related to the accuracy or integrity of any part of the work are appropriately investigated and resolved.

Funding: This study was funded by grants from the Ontario Ministry of Health and the Canadian Institutes for Health Research.

Content licence: This is an Open Access article distributed in accordance with the terms of the Creative Commons Attribution (CC BY-NC-ND 4.0) licence, which permits use, distribution and reproduction in any medium, provided that the original publication is properly cited, the use is noncommercial (i.e., research or educational use), and no modifications or adaptations are made. See: https://creativecommons.org/licenses/ by-nc-nd/4.0/

Data sharing: The authors are unable to share the underlying data because of data sharing agreements; however, these data can be purchased from IQVIA. More information is available at www.iqvia.com.

Acknowledgement: The authors thank IQVIA for the use of its Canadian Drugstore and Hospital Purchases Audit.

Disclaimer: The statements, findings, conclusions, views and opinions expressed in this report are based in part on data obtained under licence from IQVIA Solutions Canada Inc., concerning the following information services: CDH, data period Nov. 1, 2013, to Oct. 31, 2019. All rights reserved. The statements, findings, conclusions, views and opinions expressed herein are not necessarily those of IQVIA Inc. or any of its affiliated or subsidiary entities.

Supplemental information: For reviewer comments and the original submission of this manuscript, please see www.cmajopen.ca/content/9/4/ E1181/suppl/DC1. 